\title{
A arte de ver o mundo com os próprios olhos. Mãos, narizes, ouvidos e línguas ${ }^{1}$
}

Marcelo Forte ${ }^{2}$

\section{Resumo}

Esse artigo apresenta um relato de experiência de estágio supervisionado no curso de Artes Visuais - Licenciatura plena em Desenho e Plástica, com ênfase no terceiro semestre de inserção em sala de aula. Trabalhamos, professor e alunos, com a utilização de imagens da arte e de outros meios, de objetos sensoriais e da linguagem como produtores de sentidos para abordarmos os modos de ver e interpretar a imagem visual e escrita.

Palavras-chave: estágio supervisionado, interpretação, linguagem.

\section{Abstract}

This article presents an account of the experience of supervised internship in Visual Arts Class - Degree in Design and Plastic, with emphasis in the third semester of application in the class room. Together we work, teacher and students, with the use of art images and other media, sensorial objects and the language as sense producers to approach the ways of seeing and interpreting visual images.

Key-words: supervised internship, interpretation, language.

Como decifrar pictogramas de há dez mil anos

Se nem sei decifrar Minha escrita interior?

Interrogo signos dúbios E suas variações calidoscópicas A cada segundo de observação.

Carlos Drummond de Andrade

A Terra não é quadrada, é redonda. Justamente para que nós seres humanos não pensemos de maneira blocada, quadrada, com extremidades que se fecham, mas de forma redonda, para que os pensamentos sejam fluídos, movediços, permitindo que possamos mudar ao longo de nossas vidas.

E como é bom mudar, perceber que agregamos valores a cada dia, mês, ano que se passa e que deixamos para trás o que não nos interessa. O professor Dr. Flávio Gonçalves em uma palestra ${ }^{3}$ falou que a vida é editada e comecei a concordar com essa ideia, pois escolhemos as roupas que queremos usar, os programas de TV que queremos

\footnotetext{
${ }^{1}$ Pesquisa desenvolvida no terceiro semestre de estágio supervisionado do curso de Artes Visuais da UFSM.

${ }^{2}$ Formado em Artes Visuais - Licenciatura Plena em Desenho e Plástica pela Universidade Federal de Santa Maria.

${ }^{3}$ Curso de Metodologia da Pesquisa promovido pelo PPGART/UFSM.
} 
assistir, os cursos, profissões e lugares que queremos estar. Fazemos de nós o que queremos ser, mesmo sem perceber a intencionalidade de nossos atos.

Da mesma forma, atribuímos sentidos às coisas, a partir da bagagem cultural que carregamos. Somos encharcados, às vezes querendo, outras não, de produtos culturais pertencentes aos lugares onde vivemos e frequentamos, às pessoas que convivemos, às mídias e à publicidade que invade todos os dias nossas casas pela TV, pela internet e também nas ruas das cidades.

Com a arte, acredito que poderia funcionar assim também. Conferimos valor a determinado objeto artístico conforme o que vemos e sentimos, com a liberdade a que temos direito. Porém, nem sempre acontece, ou, raramente acontece. O ser humano tem medo do que é estranho, incomum, do que não está na esfera de um entendimento primeiro, por isso afasta-se. Claro que existem obras que necessitam de uma explicação, que não é somente a interpretação do público que fará a obra acontecer, mas para isso é necessário que haja o primeiro contato. A pessoa entendendo que pode entrar em contato sem necessariamente entender a obra terá menos resistência, e, portanto, mais facilidade de sorver outras ideias, de outros artistas, de outros períodos. É pensando dessa maneira que me faço artista e me torno professor de artes visuais, concordando que cada um tem um modo de ver e sentir diferente.

\section{I ntercâmbio de ideias: a arte na docência}

Hernández (2007, p.95) fala em "não se construir a partir da certeza de quem sabe, mas a partir da inquietude de quem tem e reconhece seu desejo de saber e de se conhecer." Sem certezas, mas cheio de vontades de me conhecer e entender meu processo como artista e como futuro arte-educador, vi, na construção do meu projeto de estágio, a possibilidade de investigar o que eu estava fazendo enquanto artista e de que forma aquilo poderia reverberar em meu trabalho enquanto professor de artes visuais.

Primeiramente, pensei no uso da palavra na obra de arte, pelo fato de eu bordar palavras que dizem respeito ao meu cotidiano em objetos de tecido com enchimentos. 


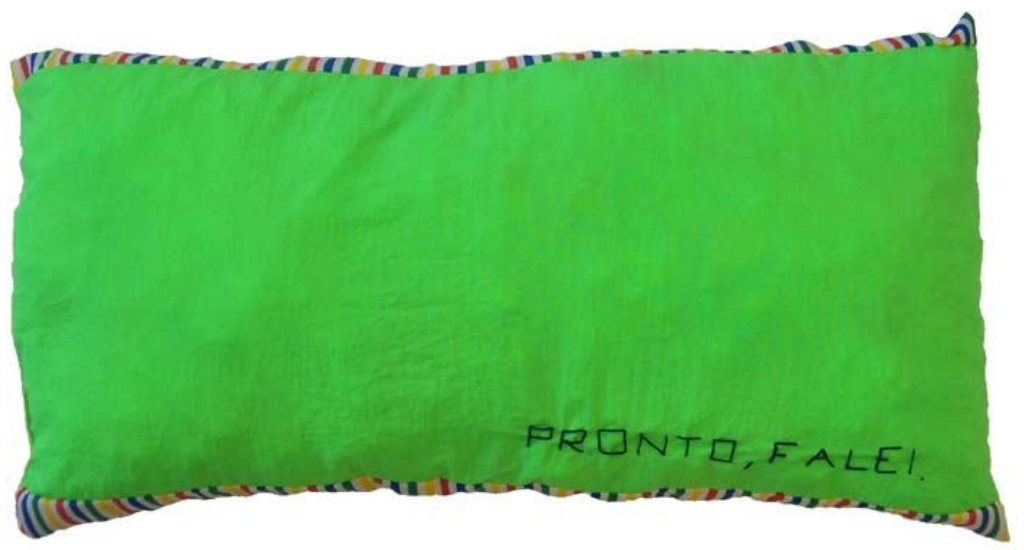

Figura. 01 Pronto, falei.

Fonte: Arquivo visual do pesquisador

Porém, logo depois comecei a pensar que eu estaria limitando a pesquisa e os próprios alunos a entrarem em contato com obras que não trazem palavras impressas, coladas, bordadas, pintadas, etc. Resolvi repensar, então. Do mesmo modo que meu projeto estava se modificando, meu trabalho artístico também estava tomando outros rumos, ganhando o espaço e necessitando da participação tátil do público. Assim, andando juntos, ambos trabalhos ganharam novas páginas e assumiram novas posições. Meus objetos explorando cada vez mais o envolvimento corporal das pessoas e meu projeto de estágio abordando os cinco sentidos nas artes visuais.

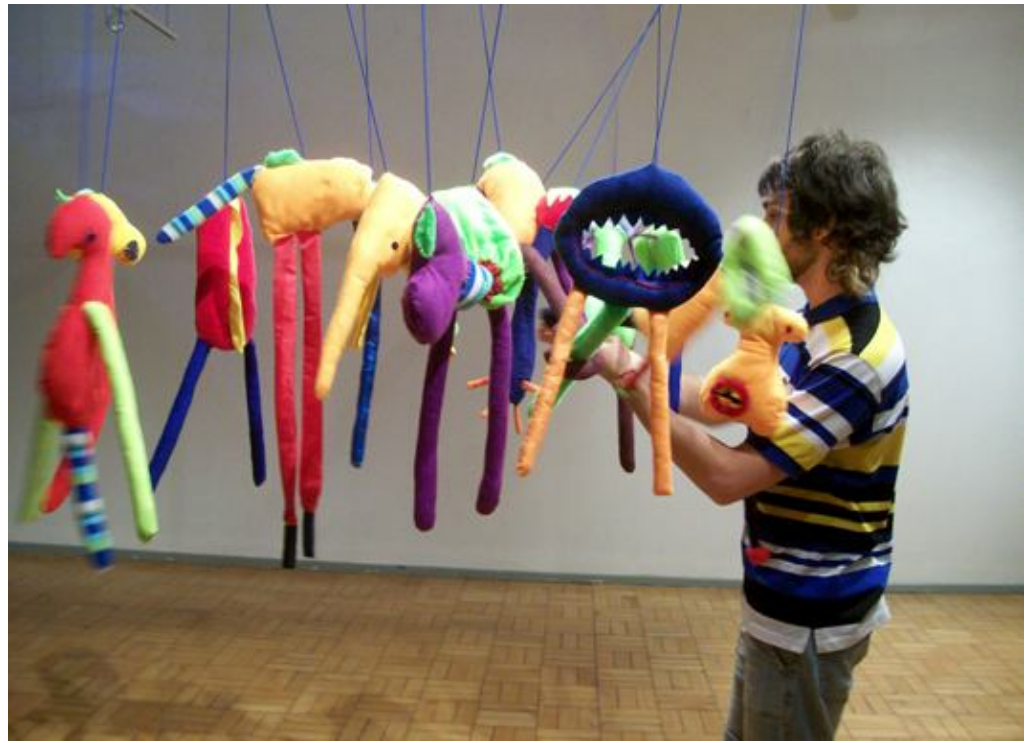

Figura. 02 Prazer.

Fonte: Arquivo visual do pesquisador 
Passado o primeiro semestre na escola, e percebido pontos positivos e negativos de meu projeto, pensei para o segundo fazer algumas alterações, levando em consideração não somente o que fazia parte de minha pesquisa, mas partindo do que a professora estava trabalhando com os alunos. E o assunto, não raro nas aulas de arte, era a semana de arte moderna, então busquei fazer relações da agitação que essas obras provocaram na época e da produção contemporânea em artes visuais, que também provoca reações diversas. Apresentei também, o movimento dadaísta,

Movimento verdadeiramente revolucionário na arte, no sentido de reformular tanto a linguagem como a atitude básica e os conceitos dos artistas diante de seu trabalho, o dadaísmo marcou indelevelmente as técnicas, os materiais e as pesquisas deste século. (OSTROWER, 2004, p. 339)

O dadaísmo entrou então em nossas aulas a fim de contextualizar um momento em que a arte apesar de parecer não fazer sentido, e de ser proclamada pelos próprios artistas como a antiarte, vinha ao encontro do que estava acontecendo na época, a guerra, o caos, a destruição.

\section{A linguagem escrita e a linguagem visual: formas de interpretação}

Para o terceiro semestre de estágio, com a turma de $1^{\text {o }}$ ano da Escola Estadual de Ensino Médio Profa Maria Rocha, decidi re-visitar os projetos passados e acrescentar novas propostas. Utilizei a palavra, não como produto visual da arte, mas como produtora de visualidades. Os objetos sensoriais também estiveram inseridos juntamente com imagens de obras de arte de diversos períodos e imagens não necessariamente artísticas, nas atividades desempenhadas pelos alunos.

Em um primeiro momento, levei objetos táteis e olfativos, imagens de revistas e de obras de arte e propus que em duplas os alunos produzissem histórias a partir daquele material. Entreguei uma imagem ou objeto para cada dupla e eles começaram a escrever. Deliberadamente, eu trocava suas imagens para que a história continuasse tomando direções inesperadas. Ao término das histórias cada dupla lia a sua. Esse trabalho possibilitou um primeiro diálogo a respeito da maneira que cada indivíduo interpreta determinada imagem e como ela pode ter significados diferentes tanto pela pessoa quanto pelo espaço e contexto ao qual se insere.

[...] a moldagem e a remoldagem de relações espaço-tempo no interior a diferentes sistemas de representação têm efeitos profundos sobre a forma como as identidades são localizadas e representadas. (HALL, 2006, p. 71) 
Assim como nos outros dois estágios, apresentei o vídeo "Quem tem medo da arte contemporânea", dirigido por Isabela Cribari e Cecília Araújo. Minha insistência em levar até os alunos esse vídeo está no fato de artistas, críticos e pessoas de áreas afins estarem nele tratando das questões atuais da arte, sobre os conceitos, os materiais não convencionais, sobre as reflexões que uma obra possibilita e também sobre a pluralidade dos sujeitos que entram em contato com ela. Acredito que o que ficou mais presente para os alunos foi a liberdade que o artista tem para criar, tanto pela forma quanto pelo conteúdo.

Além das atividades em sala de aula e sala de vídeo, eu tinha para esse semestre planejado uma saída da escola para visitar alguma exposição. Coincidiu de eu estar expondo pinturas minhas, juntamente com fotografias de outra artista. Minhas pinturas são representações dos ícones religiosos cristãos vivendo nos dias de hoje, enquanto a artista Fernanda Bona trata de diferentes mundos e apresenta em uma das fotografias sua versão para a "Alice no país das maravilhas". Com isso, pude relacionar essas obras com a atividade que eu havia designado a eles, que era partir da história que eles haviam criado e produzir um desenho. O passo seguinte seria transformar essa visualidade gráfica em uma fotografia, o que de certa forma tanto eu quanto a outra artista fizemos em nossos trabalhos. Partimos de uma história para criar uma visualidade, em linguagens diferentes. Porém, os trabalhos não corresponderam ao entusiasmo a que eles ficaram ante minha proposta.

Esse foi o momento de parar e pensar em tudo o que eu estava fazendo e pesar o que valia continuar e o que seria melhor deixar para trás. "Refletir é uma palavrinha mágica. Questionar constantemente nossa prática educativa para tentar ver onde poderíamos fazer melhor da próxima vez". (LAMPERT, 2005). Também conversei com os alunos, que concordaram que seus trabalhos poderiam ter sido feitos com mais dedicação e qualidade.

Conforme sugerido por um aluno, eles tiveram de pesquisar sobre algum artista, recomendei que procurassem por contemporâneos, para que não ficássemos somente falando dos artistas já tão trabalhados na escola, como Van Gogh, Da Vinci, Picasso, Tarsila, entre outros. Claro que mesmo com minha recomendação, esses artistas apareceram entre vários alunos. Como era uma apresentação oral, os alunos falaram um pouco da vida do artista pesquisado, mas sem apresentar imagens, então na aula seguinte, levei eu mesmo, incluindo outros artistas e períodos que eu considerei importante para o momento. 
Em uma aula seguinte, levei cartolinas coloridas, tesouras, colas e revistas e propus que criassem um "Quem sou eu?" ou "Como eu me vejo?", “Do que eu gosto?" explorando o papel (suporte), as imagens e palavras das revistas. Foi, sem dúvida, a primeira vez com essa turma que a proposição artística foi aceita e produzida com vontade, talvez pela necessidade que os adolescentes sentem de se posicionarem na sociedade, de possuírem uma identidade e de exibirem-na como assim acontece em redes sociais na internet.

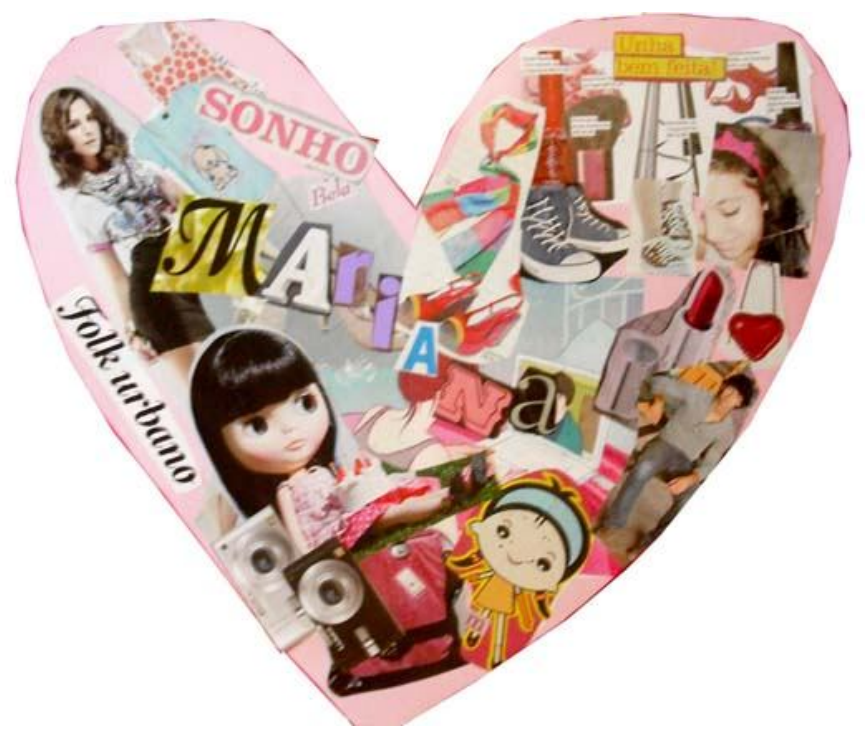

Figura. 03 Colagem 1

Fonte: Arquivo visual do pesquisador

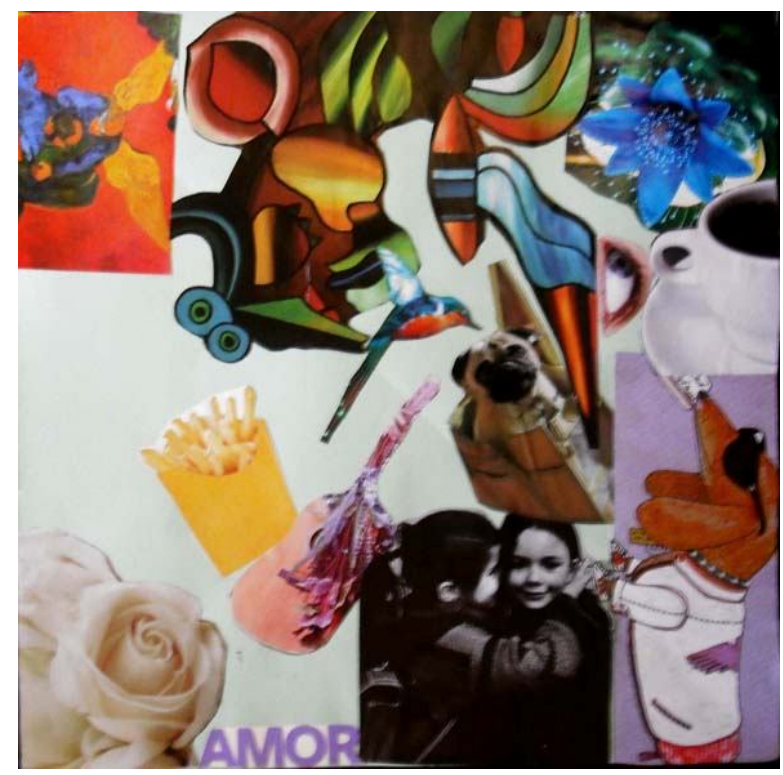

Figura. 04 Colagem 2

Fonte: Arquivo pessoal do pesquisador 
Trabalhamos também com o texto "Arte é interpretação do mundo", síntese do livro Temas de Filosofia, de Maria Lúcia de Aranha e Maria Helena Pires e Martins. No quadro, conforme um aluno ia lendo em voz alta, eu ia fazendo um esquema para melhor visualizarmos e discutirmos a respeito dos assuntos abordados pelas autoras. Percebi nessa aula que tudo o que eu havia trabalhado até então não tinha sido em vão, pois as reflexões que os alunos fizeram durante as discussões traziam um pouco de tudo o que levei desde o começo.

Na segunda parte da aula, entreguei para cada aluno uma frase retirada de livros de literatura, onde cada uma descrevia um lugar ou pessoa, ou narrava uma situação, com o propósito de que eles interpretassem essas frases, pensando diretamente no que estava escrito, ou se reportando a algum fato de suas vidas. "A linguagem, em geral, é definida como capacidade de abstração, mas na medida em que ela dá forma ao pensamento, podemos dizer que possui também uma plasticidade e, portanto, uma materialidade". (GERHEIM, 2008, p. 8). Assim, as imagens pensadas, deveriam ser desenhadas no quadro negro, para que o grupo pudesse ver e também interpretar o desenho do colega. Dessa forma, estaríamos trabalhando com a interpretação a partir da linguagem escrita, reproduzindo através da imagem gráfica, e dela, interpretando novamente em linguagem, dessa vez oral. A turma toda se envolveu nessa proposta, até que o sinal batesse e em segundos a sala se esvaziasse.

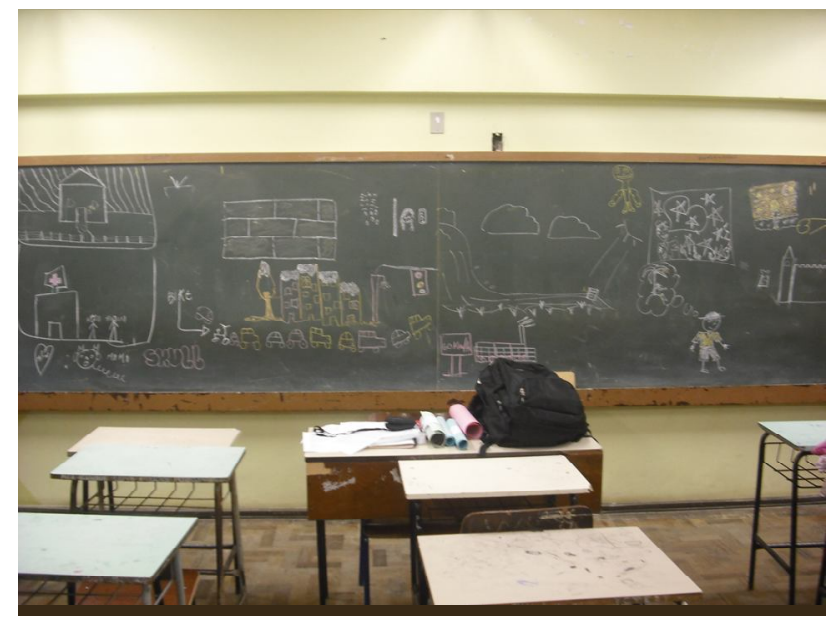

Figura. 05 - Desenho com giz

Fonte: Arquivo visual do pesquisador

Martins (2009, p. 101) ao falar sobre a interpretação das imagens, e nesse caso acredito que poderíamos inserir em meio ao seu texto a interpretação da linguagem escrita aponta que 
[...] é uma prática social que mobiliza a memória do ver e entrecruza sentidos da memória social construída pelo sujeito professor ou aluno - que interpreta. Ao interpretar, as pessoas são influenciadas pelo imaginário do lugar social em que vivem e em que vão se inscrevendo. Esse território de onde as pessoas interpretam as coloca num processo de construção de sentidos e significados, processos-atos de interpretação.

Em meio a essas aulas, também houve apresentações de imagens de arte de diferentes artistas e períodos, materiais e técnicas e formas de visualização ou contato. Read (2001) diz que "devemos observar todos os tipos de arte, e só então estaremos em condições de compreender como a arte faz apelo à imaginação", assim como um livro de literatura, onde quanto mais lermos, mais imagens criaremos em nossa mente, por isso denotei com maior ênfase em sala de aula as relações de imagem escrita, visual e imaginada.

\section{E o fluxo continua}

Minha primeira frase nesse texto foi "a terra não é quadrada, é redonda". Agora eu pergunto: lendo-a você concordou comigo (e consequentemente com Galileu) ou chegou a pensar em contestar essa verdade instituída? Amanhã ou depois poderemos descobrir que todas essas descobertas da ciência foram uma farsa e será que nosso mundo cairá por terra, com o perdão do exagero de linguagem, ou criaremos um mundo novo? Acredito na capacidade do ser humano, dos outros animais e da natureza de se moldar e se modificar conforme a situação imposta, e eu nem pesquisei Darwin. Contrariamos, sim, mas o ato de contrariar também nos molda, para um lado oposto aquele que negamos, mas com efeito, somos afetados.

Ao longo desses três semestres de estágio supervisionado, acredito ter sido esponja, metáfora que Loponte utiliza em um de seus textos (2007), pois absorvi conceitos, ensinamentos, ouvi colegas que se encontram na mesma situação, professores que sempre tem algo a acrescentar, os alunos, e me deixei inundar pelas coisas que a mim chegaram, a arte, as narrativas fílmicas, as histórias, as músicas e os encontros com pessoas, com lugares e comigo mesmo. Assim como absorvi, também passei adiante, lancei o que achava conveniente lançar, contaminei pessoas com meus pensamentos, deixando marcas horas sutis, horas tenazes, dando um pouco de mim, daquilo que um dia já foi de outros.

Da mesma forma que associei minha produção em poéticas visuais ao meu projeto de estágio, farei aqui, como encerramento, ao pensar minha formação. Concluí o curso de Artes Visuais - Licenciatura Plena, mas não me sinto formado, completo, sinto que sempre poderei ser alterado, modificado, assim como meus objetos que se conectam, se 
entrecruzam e passeiam pelos espaços, e, se fico feliz em saber que meu trabalho artístico possui esse potencial participativo e de não encerramento em si, fico mais feliz ainda em saber que também sou mutável e que posso percorrer muitos espaços.

\section{Referências}

GERHEIM, Fernando. Linguagens inventadas. Palavra imagem objeto: formas de contágio. Rio de Janeiro: Jorge Zahar Ed. 2008.

HERNÁNDEZ, Fernando. Catadores da cultura visual: transformando fragmentos em nova narrativa educacional. Porto Alegre: Mediação, 2007.

HALL, Stuart. A identidade cultural na pós-modernidade. Rio de Janeiro: DP\&A, 2006.

LAMPERT, J ociele. "Estágio supervisionado: andarilhando no caminho das Artes Visuais". In: OLIVEIRA, Marilda O. de, HERNÁNDEZ, Fernando. (Orgs.) A formação do professor e o ensino das artes visuais. Santa Maria: Ed. da UFSM, 2005. pp.147-157.

LOPONTE, Luciana Gruppelli. "Arte da docência em arte: desafios contemporâneos". In: OLIVEIRA, Marilda Oliveira de. (Org.) Arte, Educação e Cultura. Santa Maria: Ed. Da UFSM, 2007. p. 231-249.

MARTINS, Raimundo. Imagem e processos de interpretação no contexto escolar. In: ASSIS, Henrique L., TEIXEIRA, Edvânia B. (Orgs.) O ensino de Artes Visuais: desafios e possibilidades contemporâneas. Goiânia: Grafset, 2009. p. 99-106.

OSTROWER, Fayga. Universos da arte. Rio de Janeiro: Elsevier, 2004.

READ, Herbert. A educação pela arte. São Paulo: Martins Fontes. 2001. 